East African Medical Journal Vol. 80 No. 12 December 2003

LEPROSY IN NKHOTAKOTA DISTRICT HOSPITAL.

J. E. Chisi, BSc, MBBS, PhD, Senior Lecturer Department of Anatomy, College of Medicine, University of Malawi, Private Bag 360, Blantyre 3, Malawi, A. Nkhoma, Diploma in Clinical medicine, Clinical Officer, Nkhota District Hospital, Y. Zverev, MBBS, PhD, Associate Professor, Department of Physiology, H. Misiri, BSc, MSC, Lecturer, Community Health, University of Malawi and O.O. Komolafe, BVSc, PhD, Professor of Microbiology, Department of Microbiology, College of Medicine, Univeristy of Malawi, Private Bag 360, Blantyre 3, Malawi

Request for reprints to: Dr. J. E. Chisi, Department of Anatomy, College of Medicine, University of Malawi, Private Bag 360, Blantyre 3, Malawi

\title{
LEPROSY IN NKHOTAKOTA DISTRICT HOSPITAL
}

\author{
J. E. CHISI, A. NKHOMA, Y. ZVEREV, H. MISIRI and O.O KOMOLAFE
}

\begin{abstract}
Objective: To study the profile of leprosy cases at Nkhotakota District Hospital in Central Region of Malawi.

Design: Retrospective cross-sectional study of all registered cases of leprosy from records over a nine year period (January 1992 to April 2001)

Setting: Nkhotakota District Hospital-Central Region of Malawi.

Results: In total 526 cases of leprosy were identified from the records. The prevalence rates gradually increased from 0.998 per 10,000 cases in 1992 to 3.39 cases per 10,000 in 1995. There was however a gradual decline of prevalence rates from 1997/1998 that had 3.17 cases per 10,000 to 1.3 cases per 10,000 in 2001 . 1996 registered 2.34 cases per 10,000 . Fifty seven cases $(10.8 \%)$ were found with children of the age of 14 or below and $469(89.2 \%)$ cases were of adults. Paucibacillary leprosy presented with more cases than multibacillary leprosy $(\mathbf{p}<0.0000001)$. There were $80(15.2 \%)$ cases of multibacillary leprosy compared to $446(\mathbf{8 4 . 8 \%})$ cases of paucibacillary leprosy. In addition more males were affected by multibacillary leprosy than females $(p<0.0001)$ and females were more affected by paucibacillary leprosy $(p<0.01)$ than males.

Conclusion: The results show that paucibacillary leprosy though minor in Malawi can become endemic as paucibacillary leprosy is a reflection of leprosy contacts in the population. We therefore recommend continued epidemiological surveys of leprosy. Training in leprosy detection should be encouraged so that this disease can be totally eradicated in Malawi.
\end{abstract}

\section{INTRODUCTION}

Leprosy is endemic the world over(1). Programmes have been put into place to eradicate the disease(2-4). These programmes have achieved major successes and leprosy cases are now rare. In parts of the world where leprosy is still highly endemic the prevalence rates are low nearing the eradication targets. Previous studies carried out in 1994 in Karonga District in northern Malawi have shown an incidence of 11.2 cases per 10,000 persons per year(5) and India alone still contributed 70\% of the global caseload in 1996 (3). In general eradication programmes are achieving their target prevalence rates. Despite the observed successes, there are some shortcomings that may in future hinder the attainment of desired target prevalence rates by these programmes. These shortcomings include poor case finding methods(3), existence of hidden prevalence(4) making it difficult to detect the disease before complications arise, patients not completing their treatment regimes and poor knowledge of the disease by the health workers(6) among others. In spite of these shortcomings, these programmes have to be congratulated because by the end of 1997(7), about thirty five of the countries with more than 100 registered cases of leprosy had achieved a prevalence rate of less than I per 10,000 inhabitants at the national level and 17 countries $(24.6 \%)$ had prevalence rate of less than 2 per 10,000 inhabitants.

Leprosy usually presents with skin patches that have different colouration to the normal skin colour. Sometimes the initial presentation might be a neurological complication (8). A survey carried out by Robertson et al, showed that despite leprosy symptoms a lot of people $(25 \%)$ do not take appropriate action to see a medical practitioner with about $21 \%$ visiting private doctors and only $9 \%$ visiting a hospital (9). Yet delayed presentation is a known risk factor for disability in leprosy. Therefore, cases of leprosy that do come to the hospital are usually at a critical stage. Disabilities caused by this disease make it imperative that leprosy is controlled and managed adequately.

Leprosy is categorised by the amount of the bacteria in the lesion and the type of the lesion that presents. It can therefore be categorised as multibacillary (more than five skin lesions) or paucibacillary. Moreover the lesions on the skin may be classified as tuberculoid, lepromatous or indeterminate. The progression of the 
disease from infection to manifestation is very slow making it difficult to fully understand and control the spread of this disease. On the whole it is known that the disease is passed from one person to the other due to prolonged contact (10-13). Some have suggested that there might be genetic predisposition to the acquisition of this disease by an individual $(11,12)$.

A lot of studies that were done on leprosy in Malawi were in Karonga district, which is a lake shore district in Northern Malawi (5, 14-16). Since leprosy is currently a rare disease in Malawi, this study was designed to find out the number of cases that have presented to Nkhotakota district hospital, along the central region of the lake shores of Malawi in the past nine years. Therefore a study was done to find out if indeed cases of leprosy still exist along the lake shore and in the central region of the country where data on this disease is scanty if at all available. The age distribution, sex and types of leprosy lesions at presentation were determined. It is hoped that the outcome of this study will help to shape the future control programme of leprosy in the district.

\section{MATERIALS AND METHODS}

This was retrospective study carried out in Nkhotakota district hospital. Nkhotakota is located in the central region of Malawi along lake Malawi. It borders with Nkhatabay in the North East, Mzimba to the North West, Kasungu to the West, Ntchisi to the South West and Salima to the South East. The district has four traditional authorities and two sub-traditional authorities. It has 605 villages and two lakes, lake Malawi to the East and lake Chikukutu to the West. There are also two lagoons, Chia in the South East and Bana in the North East. This district has a population of about 230,361 people (17). The district covers about 4,259 square kilometres with a population density of about 54 people per square kilometre. The elevations range from 163 meters above sea level to about 500 meters. The district has a tropical humid climate with an average annual rainfall of $1600 \mathrm{~mm}$ with absolute temperature range from $29^{\circ} \mathrm{C}$ in August to $36^{\circ} \mathrm{C}$ in October.

All records compiled between January, 1992 to April 2001 in the Dermatology department of Nkhotakota district hospital were reviewed to identify all cases that had one or more anaesthetic skin patches as a standard mode of leprosy diagnosis. The monthly records of positive cases were then analysed. As this is the only hospital in the district that can treat leprosy, the records were a representation of all identified cases of the disease in the district over the nine year period. Only cases with definitive gross diagnosis and treatment regime for leprosy were included. The age, sex and type of lesions were extracted from the records of the identified cases. Statistical analysis was done using EPI INFO 2000 statistical package. A p-value of 0.05 or less was considered significant.

\section{RESULTS}

A total of 526 cases of leprosy presented to the hospital in the nine year period between January 1992 to April 2001. Of these cases $57(10.8 \%)$ were persons of 14 years or below and $469(89.2 \%)$ were people of 15 years and above. The number of male cases was 250 $(47.5 \%)$ and that of female cases was 276 (52.5\%) regardless of age. Table I shows the number of cases per year and the prevalence rate per 10,000 population each year. It can be seen that the highest prevalence rates were reported in 1995 followed by 1997 and 1998 which both had 3.17 cases per 10,000 persons. 1992 had the lowest prevalence rates of 0.998 cases per 10,000 persons. There were 80 cases of multibacillary leprosy compared to 446 cases of paucibacillary leprosy. The largest number of multibacillary cases were noted in the males in 1995 and the least were in the females in 1994 when no female presented with this type of leprosy. In contrast in 1997, 44 females presented with paucibacillary leprosy being the largest group of people. The lowest number of paucibacillary leprosy presented in 1992 also in the female population. Table 2 shows the type and sex distribution of leprosy according to age. Eighty four percent of leprosy infected people had a paucibacillary type of leprosy giving a nine year cumulative prevalence rate of 19.3 cases per 10,000 persons while $15.2 \%$ of infected people had a multibacillary type of leprosy giving a nine year cumulative prevalence rate of 3.5 cases per 10,000 persons $(\mathrm{p}<0.0000001)$. However when sex distribution is compared, males were more affected by multibacillary leprosy than females $(p<0.0001)$. In contrast, more females were affected by paucibacillary leprosy ( $\mathrm{p}<$ 0.01 ) than males. Of the 57 people in the age of 14 years and below that presented with leprosy, only four had multibacillary leprosy and the rest presented with paucibacillary leprosy. In the age range of 15 years and above, only 76 patients had multibacillary leprosy. Both sexes were equally affected by either multibacillary or paucibacillary leprosy in the youth. This was not the case in the adult patients. In the older age groups 57 males had multibacillary leprosy compared to only 19 females $(p<0.0001)$. As observed before, more females presented with paucibacillary leprosy in the older age group. The greatest numbers of leprosy were observed in the youth in 1999 all being paucibacillary leprosy cases. The least numbers of leprosy in adults were observed in 1992 and greatest numbers in 1997. As can be noted from Table 3, there were no cases of leprosy observed in the youth in 1992 . 
Table 1

Number of cases and the prevalence rate per 10,000 of population per year

\begin{tabular}{|c|c|c|c|c|c|}
\hline & Sex & $\begin{array}{l}\text { Multibacillary } \\
\text { Leprosy }\end{array}$ & $\begin{array}{l}\text { Paucibacillary } \\
\text { Leprosy }\end{array}$ & Total & $\begin{array}{l}\text { Prevalence } \\
\text { per } 10,000 \\
\text { persons }\end{array}$ \\
\hline \multirow[t]{2}{*}{1992} & Male & 6 & 10 & 16 & 0.998 \\
\hline & Female & 1 & 6 & 7 & \\
\hline \multirow[t]{2}{*}{1993} & Male & 3 & 19 & 22 & 2.65 \\
\hline & Female & 2 & 37 & 39 & \\
\hline \multirow[t]{2}{*}{1994} & Male & 7 & 26 & 33 & 3.39 \\
\hline & Female & 0 & 22 & 22 & \\
\hline \multirow[t]{2}{*}{1995} & Male & 12 & 25 & 50 & \\
\hline & Female & 1 & 27 & 28 & 2.34 \\
\hline \multirow[t]{2}{*}{1996} & Male & 10 & 15 & 25 & \\
\hline & Female & 7 & 22 & 29 & \\
\hline \multirow[t]{2}{*}{1997} & Male & 3 & 23 & 26 & 3.17 \\
\hline & Female & 3 & 44 & 47 & \\
\hline \multirow[t]{2}{*}{1998} & Male & 6 & 23 & 29 & 3.17 \\
\hline & Female & 2 & 42 & 44 & \\
\hline \multirow[t]{2}{*}{1999} & Male & 1 & 26 & 27 & 2.17 \\
\hline & Female & 1 & 22 & 23 & \\
\hline \multirow[t]{2}{*}{2000} & Male & 3 & 13 & 16 & 1.82 \\
\hline & Female & 2 & 24 & 26 & \\
\hline \multirow[t]{2}{*}{$200 I$} & Male & 8 & 11 & 19 & 1.3 \\
\hline & Female & 2 & 9 & 11 & \\
\hline Total & & 80 & 446 & 526 & 22.8 \\
\hline
\end{tabular}

Table 2

Type, age and sex distribution of leprosy at Nkhotakota District Hospital

\begin{tabular}{|c|c|c|c|c|c|c|}
\hline \multirow[b]{2}{*}{ Age Group } & \multicolumn{3}{|c|}{ Multibacillary Leprosy } & \multicolumn{3}{|c|}{ Paucibacillary Leprosy } \\
\hline & Male & Female & Total & Male & Female & Total \\
\hline $0-14$ & 2 & 2 & 4 & 26 & 27 & 53 \\
\hline $15+$ & 57 & 19 & 76 & 165 & 228 & 393 \\
\hline Total & 59 & 21 & 80 & 191 & 255 & 446 \\
\hline Percentage & 11.2 & 4 & 15.2 & 36.3 & 48.5 & 84.8 \\
\hline Cumulative & 2.56 & 0.91 & 3.5 & 8.3 & 11.0 & 19.3 \\
\hline $\begin{array}{l}\text { Prevalence } \\
\text { (rates per } 10,000 \text { ) } \\
\text { over } 9 \text { vears }\end{array}$ & & & & & & \\
\hline
\end{tabular}


Table 3

Yearly records of type of leprosy according to age

\begin{tabular}{|c|c|c|c|c|}
\hline Year & Age (years) & Multibacillary Leprosy & Paucibacillary Leprosy & Total \\
\hline \multirow[t]{2}{*}{1992} & $0-14$ & 0 & 0 & 0 \\
\hline & $15+$ & 7 & 16 & 23 \\
\hline \multirow[t]{2}{*}{1993} & $0-14$ & 1 & 5 & 6 \\
\hline & $15+$ & 4 & 51 & 55 \\
\hline \multirow[t]{2}{*}{1994} & $0-14$ & 0 & 4 & 4 \\
\hline & $15+$ & 7 & 44 & 51 \\
\hline \multirow[t]{2}{*}{1995} & $0-14$ & 0 & 7 & 7 \\
\hline & $15+$ & 13 & 45 & 58 \\
\hline \multirow[t]{2}{*}{1996} & $0-14$ & 0 & 4 & 4 \\
\hline & $15+$ & 17 & 33 & 50 \\
\hline \multirow[t]{2}{*}{1997} & $0-14$ & 0 & 7 & 7 \\
\hline & $15+$ & 6 & 60 & 66 \\
\hline \multirow[t]{2}{*}{1998} & $0-14$ & 1 & 9 & 10 \\
\hline & $15+$ & 7 & 56 & 63 \\
\hline \multirow[t]{2}{*}{1999} & $0-14$ & 0 & 11 & 11 \\
\hline & $15+$ & 2 & 37 & 39 \\
\hline \multirow[t]{2}{*}{2000} & $0-14$ & 2 & 3 & 5 \\
\hline & $15+$ & 3 & 34 & 37 \\
\hline \multirow[t]{2}{*}{2001} & $0-14$ & 0 & 3 & 3 \\
\hline & $15+$ & 10 & 17 & 27 \\
\hline \multicolumn{2}{|c|}{ Total } & 80 & 446 & 526 \\
\hline
\end{tabular}

\section{DISCUSSION}

Nkhotakota is a district along the lake shores of Malawi where historically leprosy cases have been identified(5,14-16). The highest prevalence rate registered in this study is 3.39 cases per 10,000 observed in 1995. This prevalence is lower than the incidence rate of 11.2 cases per 10,000 person years earlier found in Karonga district(5) and the prevalence rate of the Amazonas State of Brazil, which was 12.9 cases per 10,000 inhabitants in 1995(4). The nine year cumulative prevalence rate of multibacillary leprosy was lower than that of paucibacillary. This is in agreement with studies of Ponnighaus et al.(5) who also found a lower incidence of multibacillary leprosy to paucibacillary leprosy in Karonga district. Just as in their study, the majority of cases in the present study are in adult females who presented with paucibacillary lesions. In the youth both sexes are equally affected by multibacillary or paucibacillary lesions. This is in contrast with studies carried out in India where 132 cases of leprosy were detected in children of ages three to 19 years over approximately the same period of time as the current investigation. In the Indian study, multibacillary leprosy cases were higher than in the present study. Moreover, more males were infected by leprosy than females in the 10-14 year age range(18). In the current study more adult males were infected by multibacillary leprosy than females a fact that is well established in the previous studies in Malawi(13). The reverse is true for paucibacillary leprosy. The high proportion of paucibacillary leprosy observed in the present study is consistent with studies done by Mandal et al.(19). They too found a high proportion of paucibacillary leprosy and a higher incidence of leprosy cases in males in general. Their study compares well to the present study, since they too found out that males had by far the highest proportion of multibacillary leprosy and the females had more paucibacillary cases than their male counterparts. On the whole the number of the youth affected in their study was very small when compared to adults.

Since the life expectancy in Nkhotakota is 44 years for males and 47 years for females(17), the low numbers of the youth infected by leprosy is encouraging. In previous studies in Malawi, it has been shown that dwelling contacts with multibacillary patients are at five to eight fold increase risk of leprosy while those of paucibacillary contact have a two fold increased risk(13). Therefore it has been concluded that paucibacillary leprosy may not be a source of infection but a marker that one has been in contact with some outside source of infection. It is therefore possible that adults come into contact with leprosy-infected people outside their households more than the youth since the numbers of leprosy were greater in the adults than the youths. In addition studies done in Malawi have also shown that extended schooling and good housing conditions are associated with reduced leprosy(14). It is therefore possible that the youth are spending their time longer at school thereby reducing their exposure to 
mycobacterium leprae. The other explanation is that BCG vaccine might be protecting the youth from leprosy $(11,15,20)$. Since all cases of leprosy are at present recommended for multidrug therapy, it is hoped that as people get cured from their disease less cases will present to the hospital in the near future. This was observed already in 2000 when the number of cases fell to 42 from the highest number of 78 in 1995 .

The interesting observation in this investigation was that the highest number of cases were observed in the three years of 1995, 1997 and 1998. During this time, there were some funds available for active screening programme. Despite this active screening the number of multibacillary cases detected were comparable to the years when screening was not available. This is a positive development because previous studies have shown that the proportion of people with disabilities at registration, which are mainly attributed to multibacillary leprosy, were higher among males than females and also higher for passively than actively detected patients(16). As is well known that multibacillary leprosy can cause a lot more complications like cataracts(21), high rates of defaulting(22) and relapses after treatment $(23,24)$, the present investigation highlights the need for continued surveillance for leprosy. This study has also shown that leprosy though at a very small scale is a problem in Malawi and obviously there are hidden cases in the community that have to be unveiled. It is hoped that active screening will ensue along the lake shore districts so that cases of leprosy can be detected before people suffer the long-term consequences of the disease.

\section{ACKNOWLEDGEMENTS}

To Dr. Perekani, District Health Officer of Nkhotakota District Hospital for granting permission for this study and for his support during the study period and Ms A. Machonjo for secretarial services and the staff of the Department of Dermatology for assisting with data collection.

\section{REFERENCES}

1. World Health Organisation. Action programme for elimination of leprosy-status report. WHO/LEP/98.2, 1998.

2. Vijayakumaran, P., Prabhakar Rao, T. and Krishnamurthy, P. Pace of leprosy elimination and support teams in Bihar state, India. Lepr. Rev, 1999; 70:452-458.

3. Sofola, O. Leprosy elimination campaigns: the Nigerian experience. Lepr. Rev., 1990; 70:465-471.

4. Pereira, E.S., Cunha, M.G., Maroja, M. F., et al. Leprosy elimination campaign, Amazonas- Brazil 1997. Lepr. Rev. 2000; 71:77-80.

5. Ponnighaus, J.M., Fine, P.E., Sterne, J.A., et al. Incidence rates of leprosy in Karonga District, Northern Malawi: patterns by age, sex, BCG status and classification. Inte. J. Lepr. Other. Mycobact. Dis. 1994; 62:10-23.

6. Chen, S., Han, C., Li, B., Zheng, R. and Zhang, L. A survey on the knowledge and skills in the early diagnosis of leprosy in general health services at different levels in Shandong Province, the peoples' Republic of China. Lepr. Rev. 2000; 71:57-61.

7. WHO. Progress towards leprosy elimination. Wkly. Epidemiol. Rec., 1998; 73:153-160.

8. Mitchell, P.D. and Mitchell, T.N. The age-dependent deterioration in the light touch sensation on the plantar aspect of the foot in the rural community in India. Implications when screening for sensory impairment. Lepr. Rev. 2000; 71:169-178.

9. Robertson, L.M., Nicholls, P.G. and Butlin, R. Delay in the presentation and start of treatment in leprosy: Experience in the out-patient clinic in Nepal. Lepr. Rev. 2000; 71:511516.

10. Kyriakis, K.P., Kontochristopoulous G.Y. and Panteleos, D. N. Current profile of active leprosy in Greece, a five year retrospective study (1988-1992). Int. J. Lepr. Myco. Dis. 1994; 62:547-551.

11. Muliyil, J., Nelson, K.E. and Diamond, E.C. Effect of BCG on the risk of leprosy in endemic area: A case control study. Int. J. Lepr. Myco. Dis. 1991; 59:229-236.

12. Soebono, H., Giphart, M J., Schreuder, G.M., Klatser, P. R. and de Vries R. R. Associations between HLA-DRBI and leprosy in an Indonesian population. Int. J. Lepr. Myco. Dis. 1997; 65:190-196.

13. Fine, P.E, Strene, J.A., Ponnighaus, J.M., et al. Household and dwelling contact as risk factors for leprosy in Northern Malawi. Amer. J. Epid. 1997; 146:91-102.

14. Ponnighaus, J.M., Fine, P.E., Sterne, J.A., Malema, S.S., Bliss, L. and Wilson, R. J. Extended schooling and good house conditions are associated with reduced risk of leprosy in rural Malawi. Int. J. Lepr. Other. Mycobact. Dis. 1994; 62:345-352.

15. Fine, P.E., Ponninghaus, J.M., Maine, N., Clarkson, J.A. and Bliss, L. Protective efficacy of BCG against leprosy in Northern Malawi. Lancet. 1986; 2:499-502.

16. Ponninghaus, I.M., Boerrigter, G., Fine, P.E., Ponninghaus, J.M. and Russell, J. Disabilities in leprosy patients ascertained in a total population survey in Karonga District, Northern Malawi. Lepr. Rev. 1990; 61:366-374.

17. National Statistical Office, 2000. Malawi in figures (Zomba, Malawi).

18. Kaur, I., Kaur, S., Sharma, V.K. and Kumar, B. Childhood leprosy in the Northern India. Pediatr. Dermat. 1991; 8:2124 .

19. Mandal, M.G., Pal, D., Majundar, V., Biswas, P.C., Biswas, S. and Saha, B. Recent trends in leprosy in a large district of West Bengal, India, revealed by a modified leprosy campaign (MLEC). Lepr. Rev. 2000; 71:71-76.

20. Baker, D.M., Nguyen-Van-Tam, J.S. and Smith, S.J. Protective efficacy of BCG vaccine against leprosy in Southern Malawi. Epidemiol. Infect. 1993; 111:21-25.

21 Hogeweg, M. Cataract: The main cause of blindness in leprosy. Lepr. Rev. 2001; 72:139-142.

22. Griffiths, S. and Ready, N. Defaulting patterns in the provincial leprosy control programme in Northern Mozambique. Lepr. Rev. 2001; 72:199-205.

23. Gifrdhar, B. K., Girdha, A. and Kumar, A. Relapses in multibacillary leprosy patients: Effect of length of therapy. Lepr. Rev. 2000; 71:144-153.

24. Lemaster, J.W., Shwe, T., Butlin, C.R. and Roche, P.W. Prediction of highly skin smear positive cases among MB leprosy patients using clinical parameters. Lepr. Rev. 2001; 72:23-28. 